\title{
Perancangan Sistem Keamanan Parkir Sepeda Berbasis Radio Frequency Identification
}

\author{
Nurawan Rodiansyah ${ }^{1}$, Hadian Satria Utama ${ }^{2}$, Endah Setyaningsih ${ }^{3}$
}

\begin{abstract}
These day, bicycle parking is available in many places, but many people still feel the lack of security in the parking area of the bicycle. The lack of security in the bicycle parking area available today can lead to the lack of bicycle users especially in Jakarta. To re-awaken bicycle users, some bicycle parking lots are made as safe as possible so that people are interested to park their bikes in a bicycle parking area. Bicycle parking spaces are designed to lock and unlock automatically and include a messaging system using GSM module to bicycle users containing SMS messages, As well as an alarm system that emits sound. Furthermore, when users want to take the bike, users need to attach RFID card to RFID Reader. Based on the test done, the LCD display "Please Take Your Bicycle" indicates locking conditions are not locked and equipped with a delivery system in the form of SMS messages to the owner of the bike "Lock your bike burglarized, check immediately" if there is the occurrence of bicycle theft. Based on the overall test, the tool is considered to meet the design objectives of bicycle parking security system. This system can help the public to make security when the bicycle is in the bike parking area.
\end{abstract}

KEYWORDS: Alarm, Bicycle Parking, Lock and unlock automatically, Message Delivery System, Microcontroller, RFID Card

\begin{abstract}
ABSTRAK: Jaman sekarang ini, parkir sepeda sudah tersedia diberbagai tempat, namun banyak masyarakat yang masih merasakan kurangnya keamanan ditempat parkir sepeda.Kurangnya keamanan ditempat parkir sepeda yang tersedia saat ini dapat menimbulkan kurangnya pengguna sepeda khususnya di Jakarta. Untuk menyadarkan kembali pengguna sepeda, beberapa tempat parkir sepeda dibuat seaman mungkin agar masyarakat tertarik untuk parkir sepedanya ditempat parkir sepeda.Tempat parkir sepeda yang dirancang dapat mengunci dan membuka secara otomatis dan dilengkapi sistem pengiriman pesan menggunakan modul GSM ke pengguna sepeda yang berisi pesan SMS,serta dilengkapi sistem alarm yang mengeluarkan bunyi.Selanjutnya, ketika pengguna ingin mengambil sepedanya, pengguna perlu menempelkan kartu RFID ke RFID Reader. Bedasarkan pengujian yang dilakukan, pada tampilan LCD "Silahkan Ambil Sepeda Anda" menandakan kondisi pengunci sudah tidak mengunci dan dilengkapi dengan sistem pengiriman dalam bentuk pesan SMS kepada pemilik sepeda "Kunci sepeda anda dibobol, periksalah segera" jika ada terjadinya pencurian sepeda. Bedasarkan pengujian keseluruhan, alat dinilai dapat memenuhi tujuan perancangan sistem keamanan parkir sepeda. Sistem ini dapat membantu masyarakat untuk membuat keamanan saat sepedanya berada di area parkir sepeda.

KATA KUNCI: Alarm, Kartu RFID, Mengunci dan Membuka Secara Otomatis, Mikrokontroler, Parkiran Sepeda, Sistem
\end{abstract} Pengiriman Pesan

\section{PENDAHULUAN}

S epeda adalah salah satu alat transportasi yang sering digunakan oleh masyarakat untuk berpergian, sepeda ini juga bisa berfungsi mengurangi kemac etan dan polusi udara. Pada saat ini sepeda sering digunakan untuk bersenang-senang, melakukan petualangan dan menjaga kesehatan. Sepeda memiliki banyak jenisnya seperti sepeda gunung, sepeda lipat, dan lain lain.Sepeda termasuk salah satu jenis olahraga yang mudah dilaksanakan oleh segala usia, manfaatnya bagi kesehatan dapat membakar kalori, membakar lemak, mencegah penyakit jantung, meningkatkan kekuatan otot, menjaga berat badan dan lain-lain [1].

Tempat parkir sepeda adalah tempat untuk memarkirkan sepeda yang biasanya dilengkapi dengan perangkat untuk mengunci sepeda dengan menggunakan rantai. Fasilitas untuk mengunci atau merantai sepeda diperlukan mengingat terjadinya pencurian sepeda. Sepeda biasanya ditempatkan diperkantoran, perbelanjaan, dan tempat Universitas [2]. Setiap jenis sepeda memiliki ciri untuk membedakannya, tetapi itu tidak mengubah fungsi sepeda yaitu sebagai alat transportasi untuk beraktifitas, seiringnya waktu kegemaran masyarakat untuk menggunakan sepeda menjadi berkurang, dikarenakan masyarakat sekarang lebih suka menggunakan kendaraan yang lebih modern, lebih cepat dan menghemat waktu [3].

Tempat parkir sepeda merupakan tempat yang penting di sebuah Universitas, karena tanpa adanya tempat parkir sepeda yang memadai dan aman akan cukup mengganggu kenyamanan seperti terjadinya pencurian sepeda, kurangnya pengguna sepeda pada saat ini mungkin dikarenakan sistem keamanan pada parkir sepeda.Salah satu fasilitas yang tidak kalah penting adalah area parkir sepeda untuk mahasiswa, namun terdapat kurangnya sistem keamanan area parkir sepeda yang disediakan. Berdasarkan hal tersebut, dibuatlah perancangan sistem keamanan parkir sepeda pada salah satu tempat pembelajaran yang semakin banyak. Sistem parkir ini dapat diakses menggunakan kartu Radio Frequency Identification (RFID) untuk memudahkan pemakaiannya [4]. Pengunjung hanya perlu menggunakan kartu untuk mengakses pengunci pada ban sepeda dan memasukan nomor handphone untuk memberikan infomasi ke pengguna jika sepeda terjadi masalah atau ditarik paksa.

Survei dilakukan untuk membandingkan alat yang dirancang dengan alat yang sudah diciptakan. Selain itu, survei dilakukan agar dapat memahami sistem yang digunakan sehingga dapat merancang alat yang lebih baik dari alat yang ada di pasaran. Survei pertama dilakukan pada tanggal 7 Oktober 2016 di Universitas Tarumanagara kampus 1 yang berada pada jalan Letjen S.Parman No. 1 Jakarta Barat. Survei dilakukan pada siang hari untuk melihat keadaan area parkir sepeda yang tersedia pada kampus 1.Sistem pengunciannya masih

\footnotetext{
${ }^{1}$ Program Studi Teknik Elektro Universitas Tarumanagara
} 
menggunakan gembok dan rantai sebagai keamanan sepeda tersebut, selain itu masih tidak teratur dalam penempatan sepeda pada area parkir sepeda. Lahan parkir sepeda dapat dilihat pada Gambar 1.

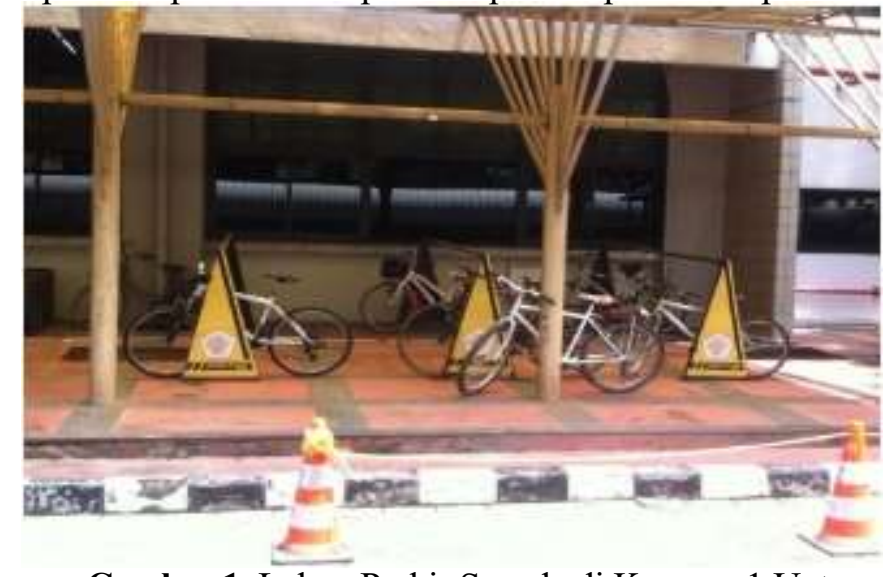

- Gambar 1. Lahan Parkir Sepeda di Kampus 1 Untar

Survei kedua dilakukan pada tanggal 20 Oktober 2016 di Universitas Tarumanagara kampus 2 yang berada pada jalan Tanjung Duren No. 1 Jakarta Barat. Survei dilakukan pada sore hari untuk melihat keadaan area parkir yang tersedia pada kampus 2, sedikitnya pengguna sepeda dikampus 2. Sistem pengunciannya masih menggunakan gembok dan rantai sebagai keamanan sepeda tersebut dan kurangnya pengguna sepeda dikampus 2. Lahan parkir dapat dilihat pada Gambar 2.

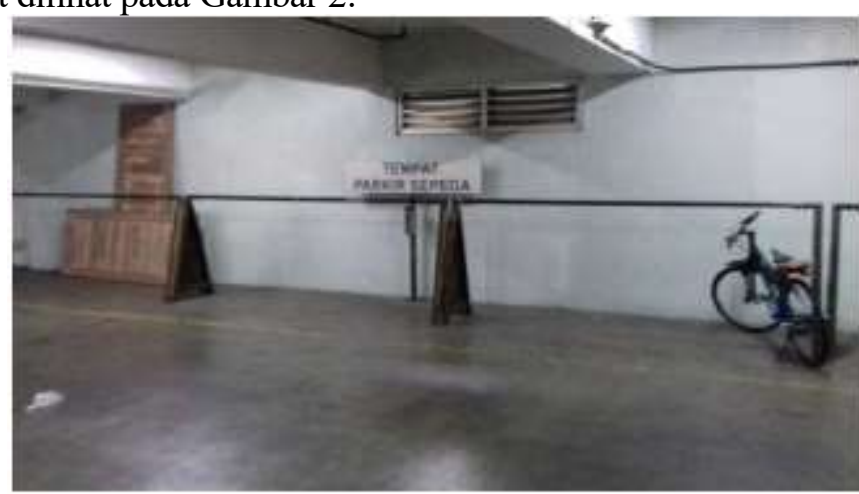

- Gambar 2. Lahan Parkir Sepeda di Kampus 2 Untar

Survei ketiga dilakukan pada tanggal 17 November 2016 di Universitas Trisakti yang berada pada jalanKyai Tapa No. 1 Jakata Barat. Survei dilakukan pada siang hari untuk melihat keadaan area parkir yang tersedia pada kampus Trisakti.Lahan parkir sepeda di Universitas Trisakti sering dipakai oleh sepeda motor disitu tertulis jelas UT Bike Parking Space, karena itu kurangnya pengguna sepeda di Universitas Trisakti sehingga sering dipakai oleh sepeda motor. Sistem pengunciannya masih menggunakan gembok dan rantai sebagai keamanan sepeda tersebut. Lahan parkir dapat dilihat pada Gambar 3.

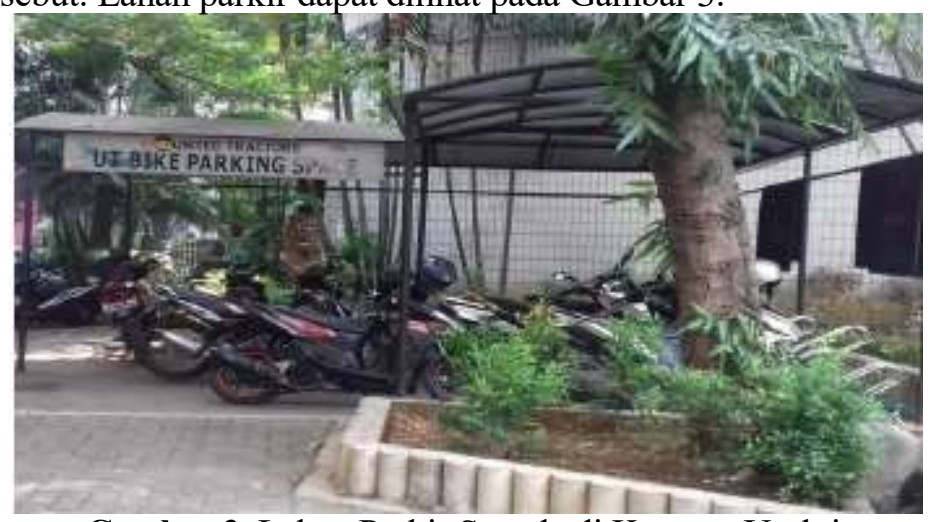

- Gambar 3. Lahan Parkir Sepeda di Kampus Usakti

Survei ke empat dilakukan pada tanggal 21 November 2016 di Universitas Indonesia yang berada pada jalan Pondok cina, Beji, Depok, Jawa Barat 16424. Survei dilakukan pada pagi hari untuk melihat keadaan area parkir yang tersedia pada kampus Universitas Indonesia. Lahan parkir sepeda di Universitas Indonesia terlihat rapih dan nyaman karena adanya pengurus parkir sepeda, banyaknya sepeda karena di sediakan oleh Universitas dan dapat digunakan oleh mahasiswa untuk beraktifitas didaerah kampus. Sistem pengunciannya masih menggunakan gembok dan rantai sebagai keamanan tersebut. Lahan parkir dapat dilihat pada Gambar 4. 


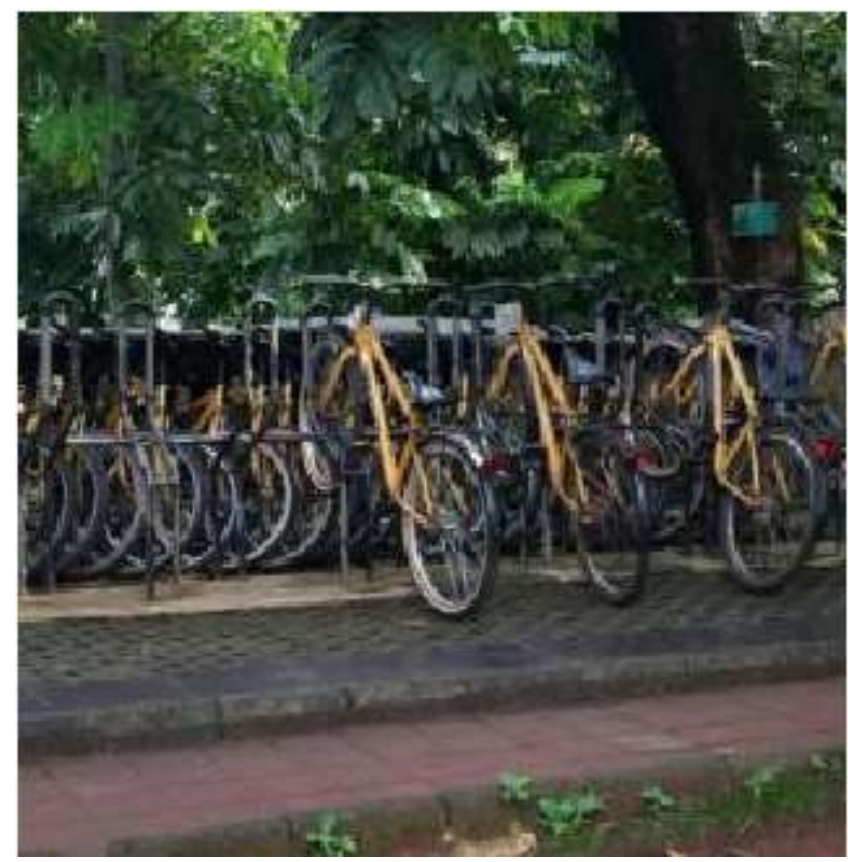

- Gambar 4. Lahan Parkir Sepeda di Kampus UI

Berdasarkan dengan hasil survei yang telah dilakukan, dapat dilihat perbandingan antara hasil survei dengan sistem yang dirancang. Perbandingan hasil survei dengan sistem yang dirancang dapat dilihat pada Tabel 1.

Tabel 1. Perbandingan Hasil Survei Dengan Alat yang Dirancang

\begin{tabular}{|c|c|c|c|c|c|}
\hline No & Parameter & $\begin{array}{c}\text { Untar 1 } \\
\text { Dan } \\
\text { Untar 2 }\end{array}$ & Usakti & UI & $\begin{array}{c}\text { Alat yang } \\
\text { Dirancang }\end{array}$ \\
\hline 1. & $\begin{array}{c}\text { Cara } \\
\text { penguncian } \\
\text { sepeda }\end{array}$ & $\begin{array}{c}\text { Penguncian } \\
\text { sepeda secara } \\
\text { manual }\end{array}$ & $\begin{array}{c}\text { Penguncian } \\
\text { sepeda secara } \\
\text { manual }\end{array}$ & $\begin{array}{c}\text { Penguncian } \\
\text { sepeda secara } \\
\text { manual }\end{array}$ & $\begin{array}{c}\text { Penguncian } \\
\text { sepeda secara } \\
\text { otomatis }\end{array}$ \\
\hline 2. & Area & $\begin{array}{c}\text { Pengawasan } \\
\text { keamanan } \\
\text { tidak terfokus }\end{array}$ & $\begin{array}{c}\text { Pengawasan } \\
\text { keamanan tidak } \\
\text { terfokus }\end{array}$ & $\begin{array}{c}\text { Pengawasan } \\
\text { keamanan } \\
\text { terfokus }\end{array}$ & $\begin{array}{c}\text { Pegawasan } \\
\text { keamanan } \\
\text { terfokus }\end{array}$ \\
\hline 3. & Fitur & $\begin{array}{c}\text { Tidak } \\
\text { menggunakan } \\
\text { Rambahan }\end{array}$ & $\begin{array}{c}\text { Tidak } \\
\text { menggunakan } \\
\text { RFID }\end{array}$ & $\begin{array}{c}\text { Tidak } \\
\text { menggunakan } \\
\text { RFID }\end{array}$ & $\begin{array}{c}\text { Menggunakan } \\
\text { RFID }\end{array}$ \\
\hline
\end{tabular}

Tujuan rancangan dan realisasi model sistem ini adalah membuat pengunci otomatis pada sepeda, selain itu sistem ini juga dapat mengirimkan informasi ke pemilik sepeda dalam bentuk pesan jika terjadi pencurian sepeda.

Model yang direalisasi memiliki batasan sebagai berikut:

- Memiliki dimensi jari-jari roda sepeda lebih dari $0,8 \mathrm{~cm}$.

- Rangka tempat sepeda dari bahan besi.

Selanjutnya pada model ini terdapat modul yang dirancang dan modul yang tidak dirancang. Modul yang dirancang dalam perancangan ini adalah:

- Modul Catu Daya

- Modul Pengunci

- Modul Tombol

Sedangkan modul yang tidak dirancang dalam perancangan ini adalah:

- Modul RFID Reader

- Modul Mikrokontroler

- Kartu RFID

- Modul GSM

- Keypad 
- $\mathrm{LCD}$

- Modul Alarm

\section{DESKRIPSI KONSEP}

Alat yang dirancang berfungsi untuk keamanan atau menjaga sepeda saat berada di area parkir sepeda, pada alat yang dirancang bertujuan untuk membantu pengguna sepeda mengetahui kondisi sepeda di area parkir sepeda, alat tersebut dilengkapi dengan sistem alarm sebagai keamanan untuk menjaga sepeda pada area parkir tersebut. Pada sistem pengunci ini dapat mengunci ban seperti ban sepeda gunung yang berukuran 66 $\mathrm{cm}$, ban sepeda lipat yang berukuran $40 \mathrm{~cm}$, ban sepeda balap $71 \mathrm{~cm}$.

Sistem perancangan ini menggunakan sistem pemroses dengan menggunakan modul mikrokontroler arduino mega dengan spesifikasi seperti catu daya 5 Volt, tengangan input 7-12 Volt, pin I/O digital 54, pin input analog 16, arus de per pin I/O 20mA, flash memroy $256 \mathrm{~KB}$, SRAM $8 \mathrm{~KB}$, EEPROM 4 KB, clock speed $16 \mathrm{MHz}$ berfungsi untuk memerintahkan instruksi ke modul-modul yang digunakan pada rancangan ini. Seperti modul GSM, modul alarm, modul tombol, modul pengunci, modul RFID, dan keypad.

Layout dari tempat parkir sepeda tampak samping dapat dilihat pada Gambar 5, flowchnart sistem keamanan parkir sepeda dapat dilihat pada Gambar 6. Tempat parkir sepeda memiliki ukuran 80 x 60 × $30 \mathrm{~cm}$.

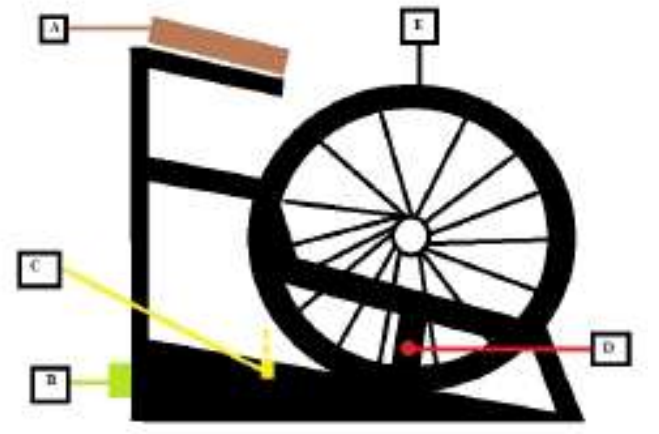

Keterangan :
A. Box Kontrol
B. Stop Kontak Listrik PLN
C. Sensor Proksimiti
D. Pengunci Ban Sepeda
E. Ban Sepeda

- Gambar 5.Tempat Parkir Sepeda Tampak Samping

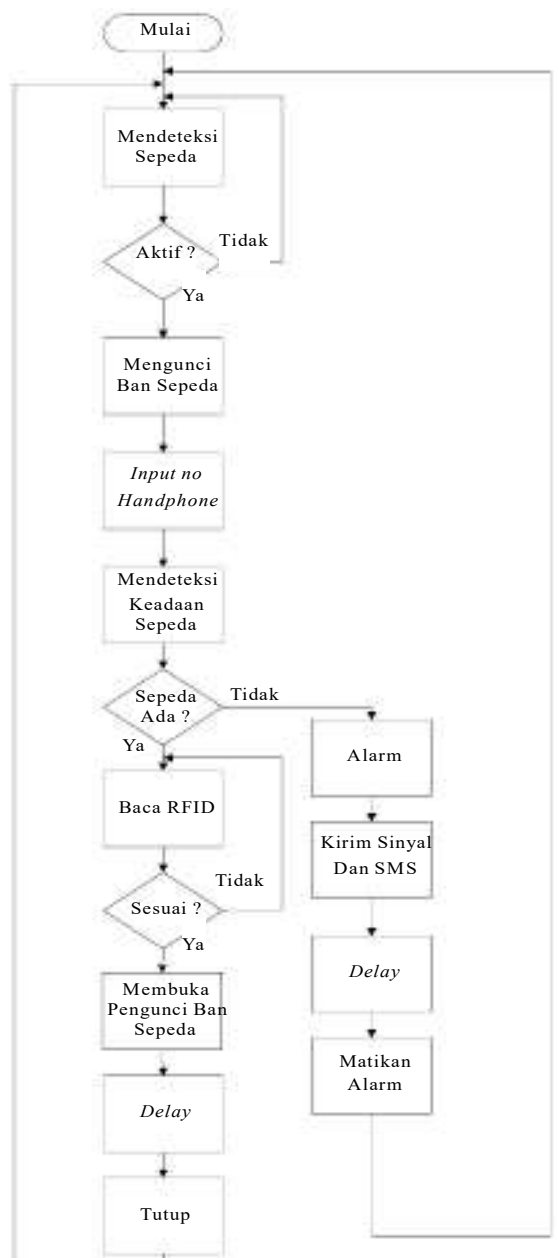

- Gambar 6. Flowchart Sistem Keamanan Parkir Sepeda 


\section{SISTEM KEAMANAN PARKIR SEPEDA}

Alat ini menggunakan pengunci otomatis, pengguna hanya perlu mendorong sepeda sampai sensor proksi membaca dan ban bagian depan pada sepeda akan terkunci, selanjutnya untuk membuka pengunci yang ada pada ban bagian depan sepeda pengguna perlu menempelkan kartu RFID ke RFID reader.

Modul penggerak motor ini menggunakan sebuah motor servo, cara kerja motor servo yaitu dapat di atur untuk menentukan dan memastikan posisi sudut yang diinginkan. Motor servo ini dapat mengatur poros untuk perputaran motor sehingga kecepatan dan arah motor dapat diatur. Cara kerja motor pada alat yang dirancang ini untuk mendorong dan menarik pengunci secara horizontal sampai terbuka dan menggunakan delay untuk menutup kembali, delay berfungsi untuk memberikan waktu selama 10 detik agar pengguna bisa mengeluarkan sepedanya dari pengunci.

Proses pengiriman informasi ke pemilik sepeda dengan menggunakan modul GSM yang diperintahkan dari modul mikrokontroler arduino mega bertujuan untuk menginformasikan jika terjadi pencurian sepeda atau sepeda ditarik paksa, pada sistem ini pengguna harus memasukkan nomor handphone pada keypad setelah memasukkan sepeda ke area parkir.

Tombol switch adalah perangkat yang berfungsi untuk menghubungkan atau memutuskan aliran arus listrik. Sistem kerja tombol switch di sini untuk menghapus nomor handphone. Ketika ingin keluar dari area parkir sepeda, pemilik harus menekan tombol reset untuk menghapus nomor handphone yang telah terintegrasi oleh sistem.

Jika terdapat masalah di sepeda seperti pencurian sepeda maka pemilik akan menerima Short Message Service (SMS) yang tertulis "Kunci sepeda Anda dibobol, periksalah segera." ke handphone pemilik sepeda, kemudian sistem alarm akan berbunyi selama 10 detik untuk memberikan informasi kebagian keamanan parkir sepeda.

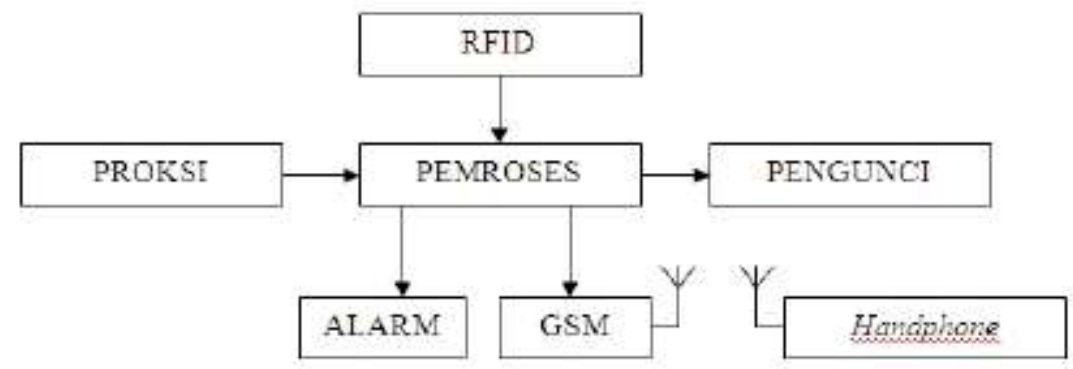

- Gambar 7. Diagram Blok Sistem Keamanan Parkir Sedpeda

\section{Mikrokontroler Arduino Mega 2560}

Pada perancangan ini mikrokontroler yang digunakan adalah ATMega 2560 yang terintegrasi dengan board Arduino Mega. ATMega 2560 ini dipilih karena sesuai dengan kebutuhan dari sistem. Ardiono Mega 2560 digunakan karena memiliki 54 pin I/O, 16 pin analog input, 4 pin Universal Asynchronous ReceiverTransmitter (UART) yang mencukupi untuk koneksi dengan berbagai modul di perancangan sistem ini. Modul Arduino Mega ini sudah terdapat built-in downloader, sehingga tidak memerlukan komponen tambahan supaya dapat terkoneksi dengan personal computer (PC). Alasan memilih tipe modul arduino mega ini karena untuk menghidupkan modul RFID dan modul GSM, karena pada modul arduino mega ini memiliki 4 pin universal asynchronous receiver-transmitter (UART) yang sudah terhubung dengan modul RFID dan modul GSM, maka untuk menjalankan modul RFID dan modul GSM dibutuhkan tipe modul Arduino Mega 2560.

Sumber tegangan dari modul Arduino Mega ini dapat dilakukan dengan dua cara, yaitu dengan menggunakan tegangan melalui port universal serial bus (USB) atau melalui power jack 2,1 mm. Arduino Mega ini dilengkapi dengan fungsi Timer 0 hingga Timer 5, serta terdapat pin inter integrated circuit (I2C). Spesifikasi untuk Arduino Mega dapat dilihat pada Tabel 2.

- Tabel 2. Spesifikasi Arduino Mega 2560

\begin{tabular}{|l|l|}
\hline Microcontroller & $\mathrm{ATmega2560}$ \\
\hline Operating Voltage & $5 \mathrm{~V}$ \\
\hline $\begin{array}{l}\text { InputVoltage } \\
\text { (recommended) }\end{array}$ & $7-12 \mathrm{~V}$ \\
\hline Input Voltage (limit) & $6-20 \mathrm{~V}$ \\
\hline Digital I/O Pins & $\begin{array}{l}54 \quad(15 \quad \text { untuk } \\
\text { PWM) }\end{array}$ \\
\hline
\end{tabular}




\begin{tabular}{|l|l|}
\hline Analog Input Pins & 16 \\
\hline DC Current per I/O Pin & $20 \mathrm{~mA}$ \\
\hline DC Current for 3.3V Pin & $50 \mathrm{~mA}$ \\
\hline Flash Memory & $256 \mathrm{~KB}$ \\
\hline SRAM & $8 \mathrm{~KB}$ \\
\hline EEPROM & $4 \mathrm{~KB}$ \\
\hline Clock Speed & $16 \mathrm{MHz}$ \\
\hline Length & $101.52 \mathrm{~mm}$ \\
\hline Width & $53.3 \mathrm{~mm}$ \\
\hline Weight & $37 \mathrm{~g}$ \\
\hline
\end{tabular}

\section{Liquid Cristal Display (LCD)}

Pada perancangan ini, digunakan media penampilan karakter dan angka pada LCD dengan ukuran 16x2. Alasan memilih ukuran 16x2 karena cukup menggunakan 16 kolom dan 2 baris. Penggunaan LCD ini hanya untuk menampilkan nomor handphone, jadi tidak dibutuhkan ukuran LCD yang besar.

\section{Kartu RFID}

Kartu RFID yang digunakan adalah kartu RFID dengan frekuensi 125khz. Penggunaan kartu RFID digunakan pada perancangan ini untuk membuka pengunci sehingga sepeda dapat dikeluarkan.

\section{RFID Reader}

RFID reader yang digunakan pada perancangan ini adalah RFID reader dengan tipe ID-12. Alasan memilih RFID reader ini karena dapat mendeteksi kartu RFID yang beroperasi pada frekuensi $125 \mathrm{khz}$. Pemilihan perangkat ini disesuaikan dengan kebutuhan pada perancangan ini. Tegangan yang digunakan yaitu 9-12VDC. Pembacaan dari kartu RFID berupa nomor serial.

\section{Keypad}

Perancangan sistem keamanan parkir sepeda ini membutuhkan media untuk memasukan nomor handphone untuk sistem keamanannya. Media yang digunakan untuk memasukan nomor handphone adalah keypad matrik 3x4, alasan memilih keypad matrik 3x4 karena cukup menggunakan 3 buah kolom dan 4 buah baris. Keypad ini dipilih karena memiliki tombol yang berjumlah dua belas sudah cukup untuk media bagi sistem ini. Keypad ini berfungsi agar pengguna dapat memasukan nomor handphone untuk tingkat kemanan sepedanya selama di area parkir.

\section{Global System for Mobile communication (GSM)}

Pada perancangan ini membutuhkan sistem pengiriman pesan ke pemilik sepeda untuk menjaga keadaan sepeda saat berada di area parkir sepeda. Untuk sistem pengiriman pesan ini menggunakan modul GSM dengan tipe SIM900A. Modul GSM ini berfungsi untuk mengirimkan informasi ke pemilik sepeda dalam bentuk pesan, alasan memiliih tipe SIM900A karena modul ini dapat bekerja dari $900 \mathrm{Mhz}$ sampai dengan 1800 Mhz. Tegangan yang digunakan oleh modul GSM yaitu 5 Vdc.

\section{Alarm}

Pada perancangan ini membutuhkan sistem alarm untuk bagian keamanan, agar dapat menjaga keadaan area parkir tersebut. Untuk menjaga sepeda, sistem alarm ini menggunakan buzzer, agar dapat didengar oleh petugas keamanan yang bertugas. Tegangan yang digunakan 3-12 VDC.

\section{Motor Servo}

Pada perancangan ini membutuhkan pengunci otomatis untuk mengunci ban sepeda. Untuk menggerakkan modul pengunci menggunakan motor servo dengan tipe MG996R, alasan memilih tipe ini karena cukup dibutuhkan dari sudut $0^{\circ}$ sampai $180^{\circ}$. Tegangan yang digunakan $4,8 \mathrm{Vdc}$ sampai $7,2 \mathrm{Vdc}$.

\section{Modul Catu Daya}

Modul catu daya digunakan sebagai sumber tegangan untuk modul-modul lainnya pada perancangan ini. Catu daya menjadi sumber tegangan untuk modul pemroses, modul GSM, modul RFID, modul pengunci, modul tombol, modul keypad, modul LCD. Oleh sebab itu, digunakan catu daya yang mampu memenuhi kebutuhan untuk perangkat-perangkat tersebut.

Modul catu daya pada perancangan alat ini berfungsi untuk memberikan supply berupa tegangan listrik yang dibutuhkan pada tiap-tiap komponen rangkaian. Pada perancangan ini memerlukan tegangan catu daya sebesar 5 VDC. Modul ini direalisasikan dengan menggunakan transformator step down untuk menurunkan 
tegangan 220 VAC. Pada modul catu daya ini terdapat 4 proses utama yaitu proses perubahan tegangan dari 220 Volt menjadi tegangan 12 VAC karena sifat yang terdapat pada transformator step down. Tegangan 12 VAC kemudian akan disearahkan pada saat melalui rangkaian dioda bridge menjadi tegangan DC, kemudian diturunkan tegangannya menjadi $5 \mathrm{Vdc}$ dengan menggunakan transistor LM7805 dan untuk menurunkan menjadi 12 Vdc menggunakan transistor LM7812.

Tegangan yang dibutuhkan untuk sistem yaitu $5 \mathrm{Vdc}$ dan $12 \mathrm{Vdc}$, pada tegangan $5 \mathrm{Vdc}$ memakain 3 buah transistor yang bernilai 3 Ampere karena total keseluruhan arus pada modul yang digunakan mencapai 1,3 Ampere, dan pada tegangan $12 \mathrm{Vdc}$ memakai 1 buah transistor yang bernilai 1 Ampere karena pemakaian arusnya yang dibutuhkan adalah $30 \mathrm{~mA}$. Skematik rangkaian modul catu daya dapat dilihat pada Gambar 8 .

\section{Modul Pengunci}

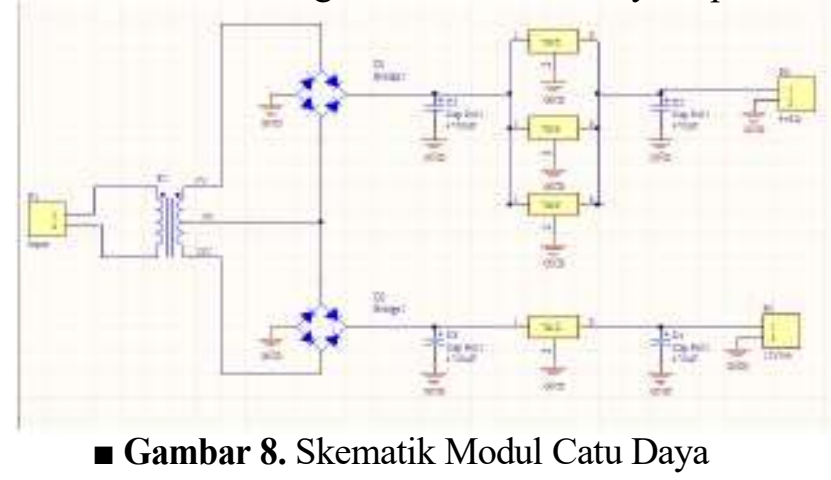

Motor servo merupakan motor DC yang digunakan untuk mengatur arah putaran motor. Kelebihan dari motor servo ini adalah dapat menentukan batas maksimum putaran sumbu motor servo. Sedangkan sudut dari sumbu motor servo diatur berdasarkan lebar pulsa pada pin kontrol motor servo. Keluaran dari motor servo ada tiga pin ke mikrokontroler.

Motor servo yang digunakan pada perancangan ini mampu bergerak dua arah yang berfungsi untuk mengunci dan membuka dengan masing-masing sudut mencapai $103^{\circ}$ sampai $180^{\circ}$. Pada prinsipnya, rangkaian motor servo ini dapat mengatur putarannya dari $0^{\circ}-180^{\circ}$ sehingga putaran motor dapat diatur dan memiliki tagangan 5VDC. Pengontrolan motor servo menggunakan mikrokontroler yang membutuhkan 3 buah pin. Dua pin untuk VCC dan GND, satu pin lagi untuk sinyal. Skematik rangkaian modul pengunci dapat dilihat pada Gambar 9.

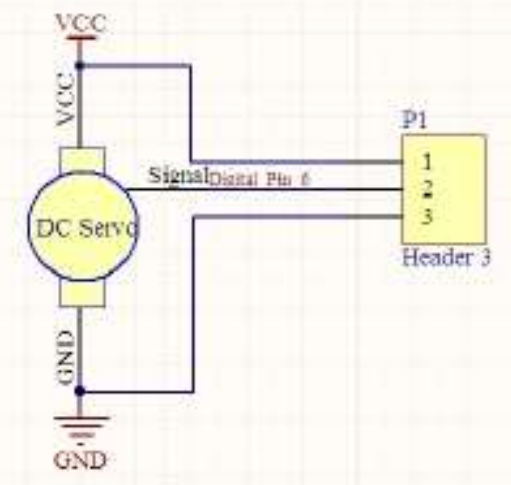

- Gambar 9. Skematik Modul Pengunci

\section{Modul Tombol}

Saklar merupakan komponen elektronika yang berfungsi untuk menghubungkan dan memutuskan suatu rangkaian. Salah satu jenis saklar adalah saklar Push ON yaitu saklar yang hanya akan menghubungkan pada saat tombolnya ditekan dan pada saat tombolnya tidak ditekan maka akan memutuskan suatu rangkaian.

Modul tombol ini menggunakan saklar push on yang dapat dioperasikan secara langsung untuk mereset atau menghapus nomor handphone, pada modul tombol ini membutuhkan 2 pin yang terhubung ke mikrokontroler yaitu ke pin reset dan pin GND dan modul tombol ini terletak di bagian depan kotak elektronik. Skematik modul tombol dapat dilihat pada Gambar 10. 


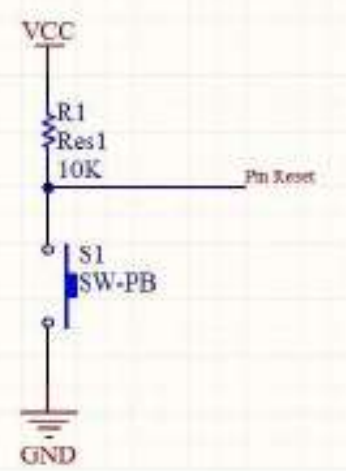

- Gambar 10. Skematik Modul Tombol

\section{Modul Catu Daya}

\section{HASIL PENGUJIAN DAN ANALISIS}

Pengukuran catu daya ini bertujuan agar dapat mengetahui kemampuan modul catu daya dalam memenuhi daya setiap modul-modul yang digunakan dan daya alat ketika semua modul sudah terintegrasi dengan baik. Pengujian tanpa beban dengan cara menghubungkan catu daya ke PLN, kemudian mengukur keluaran dengan menggunakan multimeter. Pengujian tanpa beban dilakukan pada keluaran rangkaian catu daya $5 V_{D C}$ dan $12 V_{D C}$. Tabel 3 menyajikan data hasil pengukuran tegangan input dan output dari rangkaian catu daya $5 V_{D C}$ dan $12 V_{D C}$, sedangkan Gambar 11 dan Gambar 12 menujukan data hasil pengukuran catu daya 5 $\mathrm{V}_{\mathrm{DC}}$ dan $12 \mathrm{~V}_{\mathrm{DC}}$.

- Tabel 3. Hasil Pengujian Modul Catu Daya Tanpa Beban

\begin{tabular}{|c|c|}
\hline Tegangan Input & Tegangan Output \\
$\mathrm{V}$ & $\mathrm{V}$ \\
\hline 5 & 4.97 \\
\hline 12 & 12.3 \\
\hline
\end{tabular}

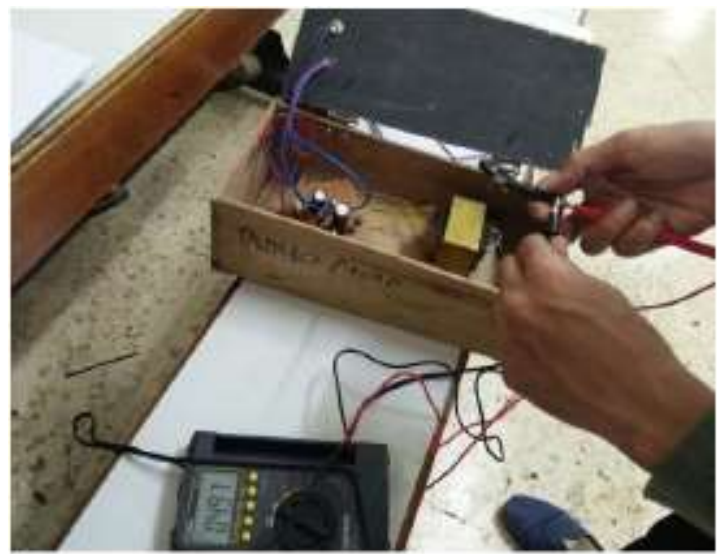

- Gambar 11. Hasil Pengujian Modul Catu Daya 5 VDC Tanpa Beban

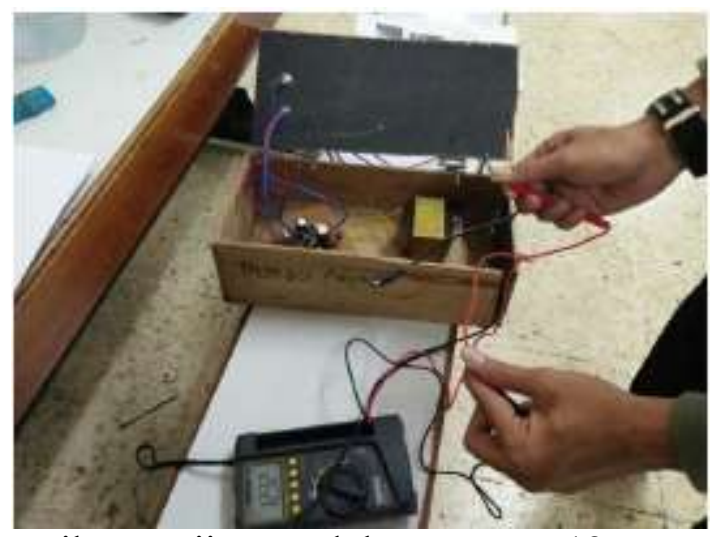

- Gambar 12. Hasil Pengujian Modul Catu Daya 12 VDC Tanpa Beban 
Modul catu daya yang digunakan pada alat yang dirancang ini memiliki tegangan keluaran 5 $\mathrm{V}_{\mathrm{DC}}, 12 \mathrm{~V}_{\mathrm{DC}}$ dan arus listrik maksimum 3 Ampere. Pengukuran dilakukan dengan mengukur arus yang terukur ketika modul-modul diberikan tegangan $5 \mathrm{~V}_{\mathrm{DC}}$ catu daya. Dengan mengukur arus listrik, maka daya yang digunakan oleh beban dapat dihitung. Semua modul yang digunakan menggunakan tegangan kerja $5 \mathrm{~V}_{\mathrm{DC}}$ dan $12 \mathrm{~V}_{\mathrm{DC}}$. Tabel 4 menyajikan data hasil pengukuran catu daya $5 \mathrm{~V}_{\mathrm{DC}}$ dan Tabel 5 hasil pengukuran catu daya $12 V_{D C}$.

- Tabel 4. Hasil Pengujian Modul Catu Daya $5 V_{D C}$ dengan Beban

\begin{tabular}{|c|c|c|c|}
\hline No & $\begin{array}{c}\text { Beban yang } \\
\text { Digunakan }\end{array}$ & $\begin{array}{c}\text { Arus Output } \\
\text { Catu Daya }\end{array}$ & $\begin{array}{c}\text { Tegangan } \\
\text { Output Catu } \\
\text { Daya }\end{array}$ \\
\hline 1 & Mikrokontroler & $50 \mathrm{~mA}$ & 4.99 Volt \\
\hline 2 & Modul GSM & $1.5 \mathrm{~mA}$ & $4.99 \mathrm{Volt}$ \\
\hline 3 & Modul Pengunci & $700 \mathrm{~mA}$ & $4.99 \mathrm{Volt}$ \\
\hline 4 & Proksimity & $300 \mathrm{~mA}$ & $4.99 \mathrm{Volt}$ \\
\hline
\end{tabular}

- Tabel 5. Hasil Pengujian Modul Catu Daya $12 \mathrm{~V}_{\mathrm{DC}}$ dengan Beban

\begin{tabular}{|c|c|c|c|}
\hline No & $\begin{array}{c}\text { Beban yang } \\
\text { Digunakan }\end{array}$ & $\begin{array}{c}\text { Arus Output } \\
\text { Catu Daya }\end{array}$ & $\begin{array}{c}\text { Tegangan } \\
\text { Output Catu } \\
\text { Daya }\end{array}$ \\
\hline 1 & RFID Reader & $30 \mathrm{~mA}$ & 12.3 Volt \\
\hline
\end{tabular}

Berdasarkan hasil pengujian ini arus total yang digunakan 1.08 Ampere, catu daya yang digunakan cukup untuk memenuhi daya kebutuhan alat yang dirancang karena arus yang dimiliki catu daya sebesar 3 Ampere. Dengan demikian, alat dapat bekerja karena mendapat daya masukan yang sesuai dengan kebutuhan.

\section{Modul Pengunci}

Modul penggerak ini menggunakan motor servo, pengujian ini memberikan input tegangan 5 $\mathrm{V}_{\mathrm{DC}}$ untuk mengaktifkan motor servo. Pengujian tersebut menggunakan bantuan dari modul catu daya $5 \mathrm{~V}_{\mathrm{DC}}$ dan pengujian modul pengunci ini menggunakan sudut $180^{\circ}$ untuk mengunci, sudut $103^{\circ}$ untuk membuka. Pada pengujian untuk membuka dan mengunci dilakukan berulangkali karena untuk memastikan dengan nilai sudut tersebut dapat mengunci dan mebuka atau tidak. Hasil pengujian hasil motor servo pada Tabel 6, Gambar 13 menunjukan hasil pengujian sudut $103^{\circ}$ kondisi membuka pengunci dan Gambar 14 menunjukan hasil pengujian sudut $180^{\circ}$ kondisi mengunci.

- Tabel 6. Hasil Pengujian Modul Pengunci

\begin{tabular}{|c|c|}
\hline Sudut & Modul Pengunci \\
\hline $180^{\circ}$ & Mengunci \\
\hline $103^{\circ}$ & Membuka \\
\hline
\end{tabular}




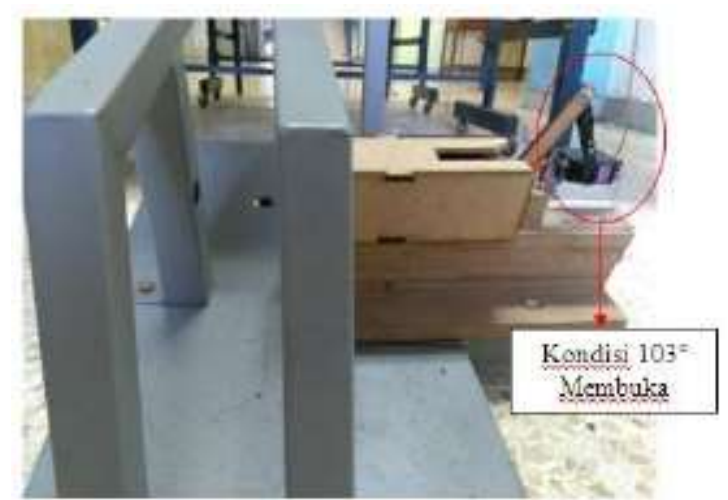

- Gambar 13. Hasil Pengujian Modul Pengunci dengan sudut $103^{\circ}$

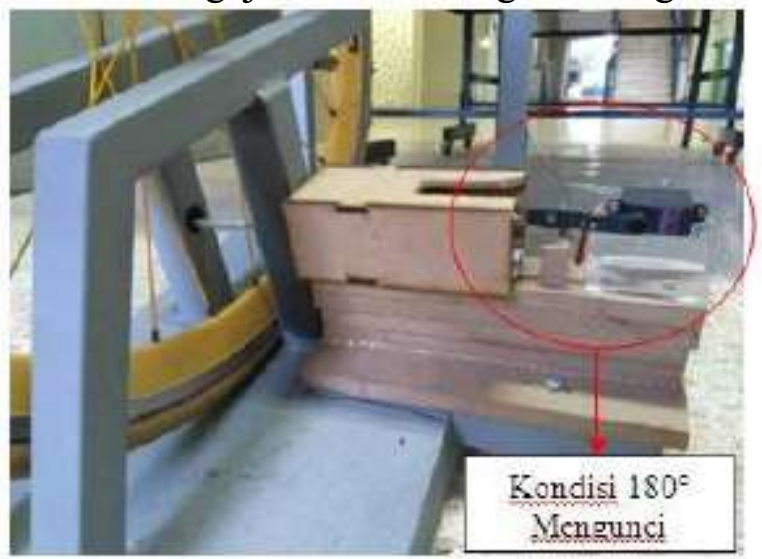

- Gambar 14. Hasil Pengujian Modul Pengunci dengan sudut $180^{\circ}$

Pada motor servo apabila diberi sudut $180^{\circ}$ yang disambungkan dengan input tegangan maka akan mengunci dan sebaliknya apabila diberi sudut $103^{\circ}$ yang disambungkan dengan input tegangan makan akan membuka. Berdasarkan hasil pengujian disimpulkan bahwa modul pengunci dapat bekerja.

\section{Modul Tombol}

Modul tombol ini menggunakan saklar push on, pengujian ini diberikan tegangan $5 V_{D C}$ dari catu dayu untuk mengaktifkan saklar push on. Pengujian tersebut menggunakan bantuan dari modul catu daya $5 \mathrm{~V}_{\mathrm{DC}}$ dan pengujian modul ini untuk menghapus nomor handphone. Pada pengujian modul tombol ini jika saklar saat ditekan keluar nilai 0 maka saklar dapat menghapus nomor handphone

Berdasarkan hasil pengujian ini, modul tombol yang digunakan untuk menghapus nomor handphone dapat bekerja karena modul saat ditekan berhasil mengeluarkan nilai tegangan $0.003 \mathrm{Vdc}$. Dengan demikian, alat dapat bekerja karena mendapat daya masukan yang sesuai dengan kebutuhan.

\section{Modul Pemroses}

Pengujian modul pemroses menggunakan mikrokontroler Arduino Mega dengan tipe ATmega 2560 dan bertujuan untuk memeriksa modul mikrokontroler dapat bekerja dengan baik atau tidak. Pengujian ini dilakukan dengan cara memberikan program sederhana untuk menguji PORT Digital mikrokontroler untuk memberikan nilai 1 untuk high, dan memberikan nilai 0 untuk Low. Program yang diuji berupa perintah untuk menampilkan LED yang menyala sesuai dengan input yang diterima mikrokontroler. Pada program diatur PORT Digital sebagai input dan GND sebagai output dihubungkan dengan LED. Hasil pengujian dapat dilihat pada Tabel 7.

- Tabel 7. Hasil Pengujian Modul Pemroses.

\begin{tabular}{|c|c|c|c|c|c|c|c|c|}
\hline No & $\begin{array}{c}\text { Pin } \\
\text { Digital } \\
7\end{array}$ & $\begin{array}{c}\text { Pin } \\
\text { Digital } \\
6\end{array}$ & $\begin{array}{c}\text { Pin } \\
\text { Digital } \\
5\end{array}$ & $\begin{array}{c}\text { Pin } \\
\text { Digital } \\
4\end{array}$ & $\begin{array}{c}\text { Pin } \\
\text { Digital }\end{array}$ & $\begin{array}{c}\text { Pin } \\
\text { Digital } \\
2\end{array}$ & $\begin{array}{c}\text { Pin } \\
\text { Digital } \\
1\end{array}$ & $\begin{array}{c}\text { Pin } \\
\text { Digital } \\
0\end{array}$ \\
\hline 1 & 0 & 0 & 0 & 0 & 0 & 0 & 0 & 1 \\
\hline 2 & 0 & 0 & 0 & 0 & 0 & 0 & 1 & 0 \\
\hline
\end{tabular}




\begin{tabular}{|l|l|l|l|l|l|l|l|l|}
\hline 3 & 0 & 0 & 0 & 0 & 0 & 1 & 0 & 0 \\
\hline 4 & 0 & 0 & 0 & 0 & 1 & 0 & 0 & 0 \\
\hline 5 & 0 & 0 & 0 & 1 & 0 & 0 & 0 & 0 \\
\hline 6 & 0 & 0 & 1 & 0 & 0 & 0 & 0 & 0 \\
\hline 7 & 0 & 1 & 0 & 0 & 0 & 0 & 0 & 0 \\
\hline 8 & 1 & 0 & 0 & 0 & 0 & 0 & 0 & 0 \\
\hline
\end{tabular}

Pengujian pada mikrokontroler berjalan sesuai dengan perintah ketika diberi nilai 1 high maka LED menyala. Berdasarkan hasil pengujian, dapat dilihat bahwa mikrokontroler dapat bekerja dengan baik karena mikrokontroler dapat bekerja sesuai dengan perintah yang dimasukkan.

\section{Modul GSM}

Pengujian modul GSM berfungsi untuk memberikan informasi ke pemilik sepeda, pesan SMS yang dikirim dari modul GSM harus sesuai dengan pesan SMS yang diterima ke handphone pemilik sepeda. Pesan SMS yang dikirim berupa huruf dan tanda baca dan pengujiannya menggunakan handphone. Hasil pengujian dapat dilihat pada Tabel 8 dan Gambar 15 menunjukan hasil pengujian modul GSM ke handphone.

- Tabel 8. Hasil Pengujian Modul GSM

\begin{tabular}{|c|c|}
\hline Pesan yang dikirim & Pesan yang diterima \\
\hline $\begin{array}{c}\text { Kunci sepeda Anda dibobol, periksalah } \\
\text { segera. }\end{array}$ & $\begin{array}{c}\text { Kunci sepeda Anda dibobol, } \\
\text { periksalah segera }\end{array}$ \\
\hline
\end{tabular}

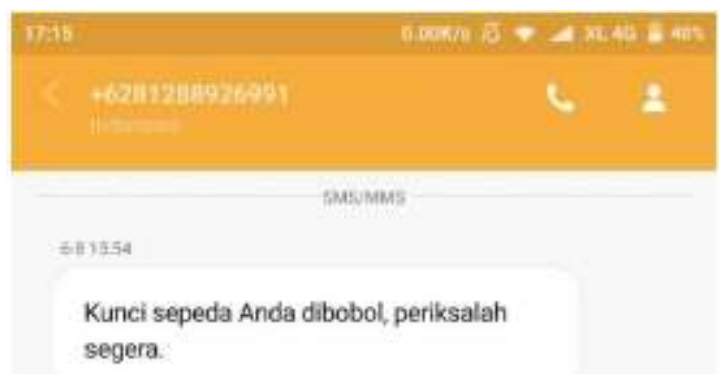

- Gambar 15. Hasil Pengujian Modul GSM ke handphone

Berdasarkan hasil pengujian, dapat dilihat bahwa modul GSM dapat bekerja dengan baik karena modul GSM dapat mengirim pesan yang sesuai dengan pesan yang diterima.

\section{PENGUJIAN DAN ANALISIS KESELURUHAN SISTEM}

Pengujian secara keseluruhan sistem dilakukan untuk melihat kemampuan gabungan seluruh modul yang disatukan dalam perancangan. Pengujian ini dikatakan berhasil apabila semua modul dalam perancangan mampu bekerja dengan baik dan sesuai dengan kondisi pengawasan keamanan terfokus untuk menjaga sepeda selama parkir di area parkir sepeda.

Pengujian pertama adalah saat sepeda berada di area parkir sepeda. Ketika terjadinya pencurian sepeda atau sepeda ditarik paksa, maka modul GSM akan mengirimkan informasi dalam bentuk SMS ke nomor handphone pemilik sepeda. Apabila pemilik lupa memasukkan nomor handphone, maka tidak ada informasi ke pemilik sepeda, jika pemilik memasukkan nomor handphone, maka akan ada informasi dalam bentuk SMS ke pemilik sepeda. Gambar 11 menunjukan hasil informasi dalam bentuk SMS dan Gambar 12 menunjukan hasil jika pengguna tidak memasukan nomor handphone. 


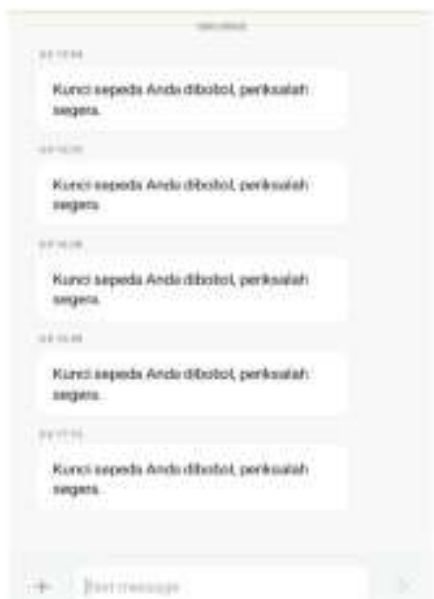

- Gambar 11. Hasil Pengujian Informasi dalam Bentuk SMS

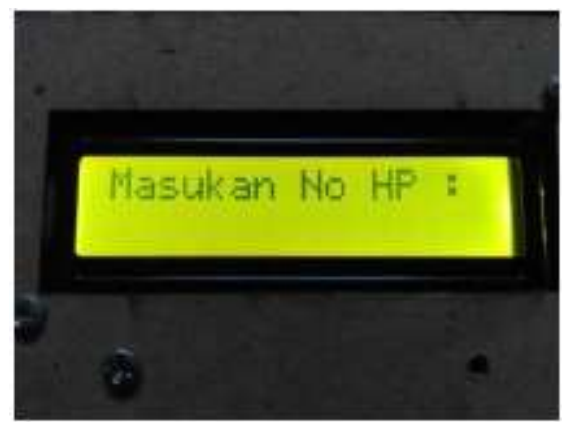

- Gambar 12. Hasil Pengujian Jika Pengguna Tidak Memasukan Nomor Handphone

Pengujian kedua adalah saat sepeda berada di area parkir sepeda. Ketika terjadinya pencurian sepeda atau sepeda ditarik paksa, maka sistem alarm akan mengeluarkan bunyi untuk mengirimkan informasi kebagian keamanan parkir sepeda. Apabila tidak mengeluarkan bunyi berarti sistem alarm tidak berjalan dengan kondisi yang seharusnya.

Pengujian terakhir adalah pengujian saat pengambilan sepeda dari tempat parkir. Kartu RFID Tag ditempelkan ke RFID reader kemudian sistem akan membuka pengunci pada ban sepeda. Apabila kartu tidak terdaftar, maka motor servo tidak akan menarik pengunci dan pengunci tidak akan terbuka. Gambar 13 menunjukan hasil pengujian kartu RFID.

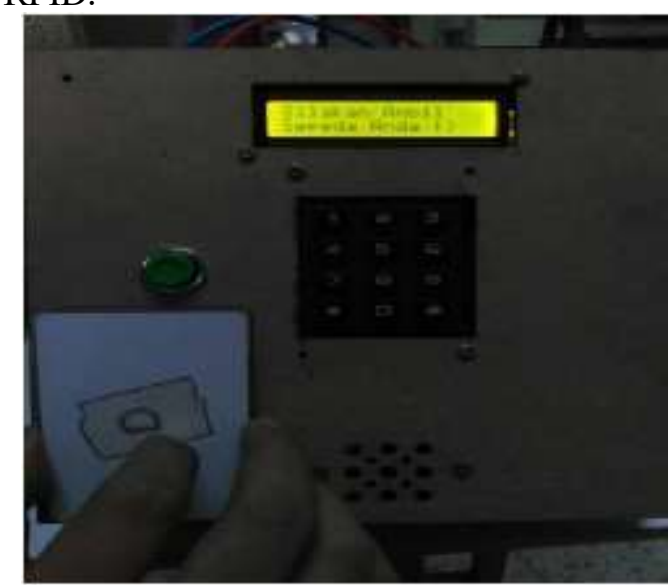

- Gambar 13. Hasil Pengujian Kartu RFID

\section{KESIMPULAN DAN SARAN}

\section{Kesimpulan}

Kesimpulan yang dapat diperoleh dari keseluruhan perancangan sistem keamanan parkir sepeda adalah sebagai berikut :

1. Tampilan pada LCD "Silahkan Ambil Sepeda Anda" menandakan kondisi pengunci sudah tidak mengunci.

2. Sistem ini dilengkapi dengan pengiriman dalam bentuk pesan SMS kepada pemilik sepeda "Kunci sepeda anda dibobol, periksalah segera", jika ada terjadinya pencurian sepeda. 
3. Bedasarkan pengujian keseluruhan, alat dinilai dapat memenuhi tujuan perancangan sistem keamanan parkir sepeda.

\section{Saran}

Perancangan sistem keamanan parkir sepeda ini masih perlu pengembangan lebih jauh dan perlu lebih baik lagi dalam pengembangan sistemnya. Saran yang dipertimbangkan sistem yang dibutuhkan untuk semua sepeda, contohnya seperti bentuk mengunci di bagian stang sepeda.

\section{DAFRTAR PUSTAKA}

[1] K.Utami,"Manfaat Bersepeda Bagi Kesehatan", Jurusan Teknologi Pangan Dan Hasil Pertanian, Fakultas Teknologi Pertanian, Universitas Gadjah Mada, Yogyakarta, Indonesia.

[2] A.Syarif dan J.Viter,"Desain Sarana Parkir Sepeda Studi Lokasi Universitas Esa Unggul”, Jurusan Desain, Fakultas Desain Dan Industri Kreatif, Universitas Esa Unggul, Jakarta, Indonesia.

[3] I.Priadythama dan B. Suhardi,"'Pengembangan Konsep Sepeda Perkotaan Dengan Mempertimbangkan Kriteria Ergonomi”, Jurusan Teknik Industri, Universitas Sebelas Maret, Surakarta, Indonesia.

[4] M.H.Firmansyah,"Keamanan Sepeda Motor Berbasis RFID Dengan Sistem Peringatan Melalui SMS Gateway”, Teknik Telekomunikasi, Fakultas Ilmu Terapan, Universitas Telkom, Bandung, Indonesia.

[5] Maryono, Dasar-Dasar Radio Frequency Identification, Jakarta: Media Informasi,2005.

[6] A. Hendriawan,'Panduan Praktikum Mikrokontoler", Teknik Elektronika, Fakultas Elektronika, Universitas Politeknik Elektronika Negri Surabaya, Surabaya, Indonesia.

[7] Data Sheet Keypad board EB014-00-1, https://www.matrixtsl.com/datasheets/EB014-30-1.pdf , Jumat 7 Juli 2017, Pukul 16.00 WIB.

[8] R. Boylestad and L. Nashelsky, Electronic Devices and Circuit Theory, 5 th ed. New Jersey. Prantice Hall, 1992, pp. 21. 763-775.

[9] M.Toha,"Sistem Alarm Anti Maling dan Anti Kebakaran Untuk Pengamanan Gedung", Teknik Elektro, Fakultas Teknik, Universitas Gunadarma, Jakarta, Indonesia. 